\title{
Biophysical regulation of stem cell behavior within the niche
}

Anthony Conway and David V Schaffer*

\begin{abstract}
Stem cells reside within most tissues throughout the lifetimes of mammalian organisms. To maintain their capacities for division and differentiation and thereby build, maintain, and regenerate organ structure and function, these cells require extensive and precise regulation, and a critical facet of this control is the local environment or niche surrounding the cell. It is well known that soluble biochemical signals play important roles within such niches, and a number of biophysical aspects of the microenvironment, including mechanical cues and spatiotemporally varying biochemical signals, have also been increasingly recognized to contribute to the repertoire of stimuli that regulate various stem cells in various tissues of both vertebrates and invertebrates. For example, biochemical factors immobilized to the extracellular matrix or the surface of neighboring cells can be spatially organized in their placement. Furthermore, the extracellular matrix provides mechanical support and regulatory information, such as its elastic modulus and interfacial topography, which modulate key aspects of stem cell behavior. Numerous examples of each of these modes of regulation indicate that biophysical aspects of the niche must be appreciated and studied in conjunction with its biochemical properties.
\end{abstract}

\section{Introduction}

The concept that the behavior of a stem cell can be modulated by factors in its immediate vicinity arose several decades ago in studies of spleen colony-forming cells, which were later appreciated to be hematopoietic stem and progenitor cells (HSPCs) [1]. It was hypothesized that these HSPCs and their progeny were distinct cell populations that possessed an 'age structure', such

*Correspondence: schaffer@berkeley.edu

Department of Chemical and Biomolecular Engineering, 201 Gilman Hall, University of California Berkeley, Berkeley, CA 94720, USA that once the progeny left their stem cell niche during developmental 'aging', their stem-like qualities were lost, and entry into a new niche promoted differentiation into a more mature, lineage-committed cell type. Subsequent work with Drosophila germ stem cells [2] and other systems demonstrated that the niche is a region that regulates stem cell fate decisions by presenting that cell with specific repertoires of soluble and immobilized extracellular factors. It is increasingly appreciated that many of these signals are biophysical in nature, particularly biochemical factors that are spatiotemporally modulated, mechanical cues, and electrostatic cues. Over the past several years, numerous examples in which the first two of these properties in particular have been shown to play key regulatory roles have emerged.

\section{Spatial organization of cues in the niche}

Many factors that are often thought of as soluble are known to harbor matrix-binding domains that immobilize them to the solid phase of tissue. For example, fibroblast growth factors, platelet-derived growth factors (PDGFs), transforming growth factors (TGFs), vascular endothelial growth factors (VEGFs), Hedgehogs, and numerous cytokines contain heparin-binding domains [3-6]. Immobilization of such factors to the extracellular matrix (ECM) often modulates their activity by promoting sustained signaling via inhibiting receptor-mediated endocytosis [7], increasing their local concentration and establishing concentration gradients emanating from the source [8], and otherwise modulating the spatial organization of factors in a manner that affects signaling. As an example, compared with soluble VEGF, VEGF bound to collagen preferentially activates VEGFR2, associates with $\beta 1$ integrins, and promotes the association of all of these molecules into focal adhesions [9]. There are also strong examples of synthetic systems that harness these phenomena, the first of which involved tethering epidermal growth factor to immobilized poly(ethylene oxide) (PEO) to prolong growth factor signaling in rat hepatocyte cultures [10]. A subsequent study showed that immobilization of Sonic hedgehog (Shh) onto interpenetrating polymer network surfaces, along with the integrinengaging peptide arginine-glycine-asparagine (RGD), 
induced potent osteoblastic differentiation of bone marrow-derived mesenchymal stem cells (MSCs), whereas soluble Shh enhanced proliferation [11]. As another example, crosslinking heparin-binding peptides to fibrin gels along with neurotrophic factor 3 (NT-3) and PDGF resulted in neuronal and oligodendrocytic differentiation of mouse neural stem cells (NSCs) with inhibition of astrocytic differentiation [12]. Finally, immobilization of leukemia inhibitory factor (LIF) to a synthetic polymer surface supported mouse embryonic stem cell (mESC) pluripotency for up to two weeks in the absence of soluble LIF, indicating the advantage of substrate functionalization in lowering cell culture reagent costs and facilitating future multifactorial cell fate screening experiments [13].

Immobilization of cues to the solid phase - that is, the ECM or the surface of adjacent cells or both - also offers the opportunity to modulate the nanoscale organization in which these factors are presented (Figure 1). Growing evidence has indicated that ligand multivalency, or the number of ligands organized into a nanoscale cluster, can exert potent effects on cell behavior [14-17]. For example, seminal work using a synthetic system to present clusters of ECM-derived adhesion ligands showed that the spatial organization of ECM cues can also impact cell responses. Specifically, on surfaces functionalized with the integrin adhesion ligand YGRGD in various states of valency, fibroblast attachment did not vary as a function of ligand valency, yet substrates bearing highly clustered or multivalent peptides required significantly lower ligand densities to induce cell spreading and migration [18]. In recent work that explored the behavior of MSCs in a three-dimensional (3D) hydrogel functionalized with RGD peptides, investigators who used a fluorescence resonance energy transfer technique found that the cells apparently reorganized the peptides into clusters upon integrin binding [19].

The role of ligand clustering also extends to growth factors and morphogens. The morphogen Hedgehog and its family member Shh, best known for their role in tissue patterning during development, have been shown to require nanoscale clustering to achieve long-range paracrine signaling [20]. Additionally, transforming growth factor-beta (TGF- $\beta$ ) is able to induce distinct differential signaling by activating either a homomeric or a heteromeric form of its receptor, which needs to be dimerized or tetramerized before signaling can occur [21]. Furthermore, cell membrane-bound ligands (for example, Delta/ Jagged that activate the Notch receptor and ephrins that activate corresponding Eph receptors) often require oligomerization to transduce biochemical signaling cascades $[22,23]$. The creation of synthetically clustered, or multivalent, ligands offers a useful tool to study basic biological aspects of receptor clustering as well as a reagent to better control stem cell self-renewal or differentiation. For example, Shh has been chemically conjugated to the long polymer chain hyaluronic acid at varying stochiometric ratios to produce a range of multivalent forms of Shh, and higher-valency Shh bioconjugates exerted progressively higher potencies in inducing the osteogenic differentiation of a primary fibroblast line with MSC characteristics [24]. This concept was recently extended to create highly active and multivalent versions of ligands that are naturally integral membrane proteins (A Conway, $\mathrm{T}$ Vazin, N Rode, KE Healy, RS Kane, DV Schaffer, unpublished data).

In addition to spatial regulation of cues at the nanoscale, microscale features in the niche can play key roles. Fibrous ECM proteins such as collagen and fibronectin are present throughout the NSC niche, raising the hypothesis that cells may respond to ECM surface topography. One interesting demonstration of this idea showed that rat NSCs cultured on laminin-coated synthetic polyethersulfone fibers of 280 or $1,500 \mathrm{~nm}$ in diameter preferentially differentiated into oligodendrocytes or neurons, respectively. It has also been shown that culturing MSCs atop vertically oriented nanotubes of 70 to $100 \mathrm{~nm}$ in diameter (but not less than $30 \mathrm{~nm}$ ) is sufficient to induce their differentiation into osteoblasts [25]. In an analogous study, culturing MSCs on nanopits of $100 \mathrm{~nm}$ also induces osteogenesis but only if the pits are anisotropic, or disordered [26]. Recently, the cytoskeletal scaffolding protein zyxin was shown to play an important role in the response of human MSCs to surface nanotopography [27]. Specifically, MSCs expressed zyxin at lower levels when plated on a polydimethylsiloxane (PDMS) surface patterned with a 350-nm grating, which resulted in smaller and more dynamic focal adhesions and increased directional migration of the cells along the gratings.

In addition to nanoscale features, cell-cell interactions at the microscale affect behavior. Specifically, the assembly of stem cells themselves into multicellular aggregates exerts strong influences on cell self-renewal or differentiation, as the cells actively secrete factors and modulate local biological transport properties in ways that impact their neighbors. For example, several groups have created controlled 3D culture systems to generate human embryonic stem cell (hESC) embryoid bodies (EBs) - or cell clusters - of defined sizes. These involved centrifugalforced aggregation [28] as well as microfabricated PDMS wells surrounded with functionalized protein-resistant self-assembled monolayers [29]. These methods produced more consistent sizes than EB suspensions, and in the latter example a tighter distribution of $\mathrm{EB}$ volume was accompanied by a higher level of expression of the pluripotency marker Oct-4. In another key study, hESC culture inside microfabricated poly(ethylene glycol) 


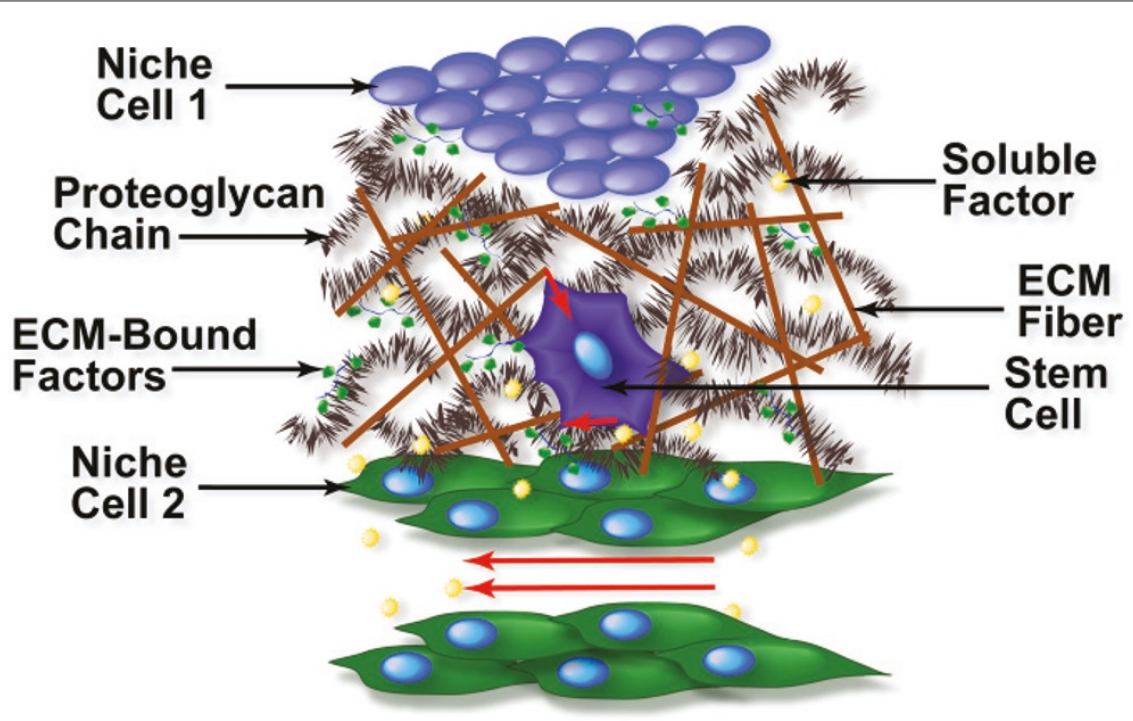

Figure 1. Mechanical and biophysical interactions in the stem cell niche. The native microenvironment, or niche, in which a stem cell resides can be highly complex, consisting of various cell types, extracellular matrix (ECM) molecules, and growth factors. Proteoglycans and ECM proteins bind and immobilize otherwise soluble growth factors, providing functional sites for cell binding as well as mechanical stability of the space surrounding a stem cell in its niche. ECM fibers and neighboring niche cells provide mechanical support and stimuli (short red arrows) to influence stem cell fate. The degree of 'crosslinking' of the various ECM molecules also affects the pore size in the niche, dictating the rate of diffusion of soluble factors as well as the ability of niche cells to infiltrate nearby space. Finally, flow through local vasculature (long red arrows) mechanically shears endothelial and other cells (green), which may in turn affect nearby stem cells.

(PEG) wells yielded EBs from 40 to $450 \mu \mathrm{m}$ in diameter [30,31]. Greater endothelial cell differentiation was observed in smaller EBs $(150 \mu \mathrm{m})$, which was shown to be due to higher Wnt5a expression, whereas larger EBs $(450 \mu \mathrm{m})$ enhanced cardiogenesis as a result of higher Wnt11 expression. Interestingly, another group used microcontact printing of adhesive islands on twodimensional substrates to control hESC colony size and showed that smaller hESC colonies became more endoderm-biased, whereas larger colonies exhibited greater differentiation into neural lineages [32]. Within the endoderm-biased colonies, cardiogenesis was found to be more pronounced in larger EBs as opposed to the neural-biased colonies, which had higher levels of cardiogenesis in smaller EBs. Collectively, these results demonstrate that spatial organization of molecules and cells can play critical roles in modulating stem cell fate and can therefore serve as important tools to exert exogenous control over these processes.

\section{Mechanoregulation in the niche}

The mechanical properties of tissues have been studied for a number of decades. In the 1950s, it was observed that cells of the mesenchyme grow preferentially toward regions that are under higher mechanical stress, indicating a fundamental contribution of mechanical properties to biological function [33,34]. Aberrant tissueelastic mechanical properties have also been shown to play a pathological role in certain cases, such as causing increased contractility of arterial resistance vessels within hypertensive rats, leading to elevated blood pressure and eventual heart failure [35]. There is a strong rationale for why mechanical properties may also modulate stem cell behavior. Tissues in the body range over several orders of magnitude in stiffness, from the softness of adipose to the toughness of bone, hinting at the possible importance of mechanics in maintaining different adult organs. In addition, there is local heterogeneity within individual tissues, as it has been shown, for example, that the hippocampus - a brain region that harbors adult NSCs spatially varies in stiffness, as assessed by atomic force microscopy [36]. These various differences are not captured in the hard tissue culture surfaces typically used for in vitro study.

Engler and colleagues [37], in pioneering work, demonstrated that substrate elastic modulus affects stem cell lineage commitment, in which MSCs cultured on polyacrylamide substrates of varying elastic moduli differentiated into cell types characteristic of tissues with the corresponding stiffness: neurons, myoblasts, and osteoblasts. A later study extended this concept to another stem cell type by showing that NSCs cultured on variable modulus substrates differentiate preferentially into neurons on softer substrates and astrocytes on harder materials [38]. Recently, it was shown that soft substrates enhance the ability of human embryonic and human-induced 
pluripotent stem cells to differentiate into neural lineages [39].

The finding that increased matrix rigidity can modulate cell differentiation has also been extended to analysis of the epithelial-mesenchymal transition (EMT) of both murine mammary gland cells and canine kidney epithelial cells, where more rigid substrates promoted EMT via upregulating the Akt signaling pathway [40]. In addition to differentiation on a single stiffness, durotaxis - the ability of cells to migrate in response to a stiffness gradient - and mechanosensitive differentiation can be integrated. For example, upon seeding of MSCs on a surface with a gradient in stiffness, cells migrated preferentially toward the stiffer region of the gel and then differentiated according to the local stiffness [41]. Finally, stem cells can, in turn, strongly influence their mechanical environment. MSCs cultured on non-linear strainstiffening fibrin gels have been shown, upon application of local strain via cytoskeletal rearrangement and cell spreading, to globally stiffen the gel [42]. This effect led to long-distance cell-cell communication and alignment, thus indicating that cells can be acutely responsive to the non-linear elasticity of their substrates and can manipulate this rheological property to induce patterning.

In addition to differentiation, modulus can influence stem cell self-renewal. For example, it was shown that substrate stiffness strongly impacts the ability of muscle stem cells, or satellite cells, to undergo self-renewal in culture. Upon implantation, cells isolated from muscle and grown on soft substrates were able to expand and contribute to muscle to a much greater extent than stem cells cultured on stiff surfaces [43]. Furthermore, mESC self-renewal is promoted on soft substrates, accompanied by downregulation cell-matrix tractions [44].

Mechanobiologists have begun to elucidate mechanisms by which stem cells undergo mechanoregulation, building on advances with non-stem cells. Several mechanotransductive proteins involved with producing traction forces via cytoskeletal rearrangements are thought to be implicated in translating mechanical signals into changes in gene expression in stem cells $[37,45,46]$. For example, it has been shown that inhibition of myosin II diminishes the effect of ECM stiffness on MSC differentiation [37]. Furthermore, decreasing ECM stiffness decreases RhoA activity and subsequent calcium signaling in MSCs [47]. Recent work also indicates that Rho GTPases, specifically RhoA and Cdc42, enable NSCs to adjust their own stiffness as a function of the substrate modulus and thereby regulate the cells' stiffnessdependent differentiation into either astrocytes or neurons in vitro and potentially in vivo [46]. Furthermore, an important study demonstrated that the transcriptional coactivator YAP undergoes nuclear localization in MSCs on higher-stiffness substrates, thereby narrowing the gap in our understanding of how microenvironmental mechanical properties may ultimately modulate gene expression and, as a result, cell differentiation [48]. Finally, while mechanosensitive stem cell behavior has been demonstrated on several materials in addition to the original polyacrylamide, recent work broaches another possible mechanism for cell behavior on different stiffnesses. Specifically, investigators found that MSCs exhibited different behavior on polyacrylamide but not PDMS gels of variable modulus, and additionally found that the porosity of the polyacrylamide but not the PDMS gels varied with stiffness. This raised the intriguing possibility that differences in ECM conjugation specifically the number of anchoring points of collagen to the gel surface - could subsequently affect integrin binding and thereby modulate cell responses [49]. This possibility should be explored further, potentially in comparison with findings that NSCs and MSCs on polyacrylamide-based materials behave similarly as a function of modulus for materials presenting either ECM proteins $[37,46]$ or simple RGD peptides $[19,38]$.

In addition to the static mechanical properties of cells and surrounding tissue, dynamic biomechanical processes can regulate stem cell function. For instance, stress and strain from local tissue contraction and expansion, including processes such as contraction of muscle, tendons, and ligaments as well as cyclic deformation of tissue surrounding vasculature and the lungs, are prevalent in vivo. Furthermore, organismal development is a highly dynamic process that exposes cells and structures to mechanical forces. In Drosophila embryos, for example, compression of cells induces expression of Twist, a protein involved with regulating germ layer specification and patterning [50]. Similarly, in zebrafish, tensile strains were shown to regulate gastrulation during early development [51]. Such basic studies extend to mammalian stem cells. For example, cyclic strain of lung embryonic MSCs stimulates expression and nuclear localization of tension-induced/inhibited protein-1 (TIP-1) and inhibits expression of TIP-3, thereby promoting myogenesis and inhibiting adipogenesis [52]. Cyclical stretching also inhibits differentiation of hESCs through upregulation of Nodal, Activin A, and TGF $\beta 1$ [53]. Differential effects of equiaxial versus uniaxial strain have also been observed, with equiaxial primarily downregulating smooth muscle cell promoting factors in MSCs and uniaxial upregulating them [54].

Even temporal variation of the ECM on slower timescales may play a role in regulating stem cell function [55]. For example, matrix metalloproteinases (MMPs), enzymes that remodel the ECM through cleavage of key constituent proteins, can modulate stem cell differentiation. Interestingly, it has been shown that, in response to two injury-induced chemokines, SDF-1 and VEGF, 
Table 1. Examples of biophysical regulation within the stem cell niche

\begin{tabular}{|c|c|c|c|c|}
\hline $\begin{array}{l}\text { Biophysical } \\
\text { property }\end{array}$ & Stimulus & Cell type & Response & References \\
\hline $\begin{array}{l}\text { Ligand-substrate } \\
\text { immobilization }\end{array}$ & $\begin{array}{l}\text { VEGF; EGF; Shh; NT-3, } \\
\text { PDGF; LIF, SCF }\end{array}$ & $\begin{array}{l}\text { Human endothelial cells; } \\
\text { rat hepatocytes; rat MSCs; } \\
\text { hESC-derived NPCs; mESCs }\end{array}$ & $\begin{array}{l}\text { VEGFR2 activation; DNA synthesis; osteoblast } \\
\text { differentiation; decreased astrogensis; STAT3/MAPK } \\
\text { activation }\end{array}$ & $\begin{array}{l}\text { [9]; [10]; [11]; } \\
\quad[12] ;[13]\end{array}$ \\
\hline $\begin{array}{l}\text { Multivalent } \\
\text { presentation }\end{array}$ & Galactose; RGD; Hh; TGF- $\beta$; Shh & $\begin{array}{l}\text { Escherichia coli; mouse } \\
\text { fibroblasts; Drosophila; } \\
\text { mink lung epithelial } \\
\text { cells; mouse embryonic } \\
\text { C3H10T1/2 cells }\end{array}$ & $\begin{array}{l}\text { Chemotaxis; motility/adhesion; patched activation; } \\
\text { endocytosis; osteogenic differentiation }\end{array}$ & $\begin{array}{l}\text { [16]; [18]; [20]; } \\
\quad[21] ;[24]\end{array}$ \\
\hline Surface topography & $\begin{array}{l}\text { 70- to } 100-n m \text { nanotubes; } \\
\text { nanotopographical disorder; } \\
\text { 350-nm gratings; decreased } \\
\text { collagen-anchoring sites }\end{array}$ & $\begin{array}{l}\text { hMSCs; hMSCs; hMSCs; } \\
\text { human epidermal stem } \\
\text { cells }\end{array}$ & $\begin{array}{l}\text { Osteoblast differentiation; bone ECM formation; } \\
\text { decreased zyxin/increased motility; increased } \\
\text { differentiation }\end{array}$ & $\begin{array}{l}{[25] ;[26] ;} \\
{[27] ;[49]}\end{array}$ \\
\hline $\begin{array}{l}\text { Physical orientation } \\
\text { of stem cells }\end{array}$ & $\begin{array}{l}450-\mu m \text { cell cluster size/ } \\
150-\mu m \text { cell cluster size; } \\
\text { decreased cell colony size }\end{array}$ & mESCs; hESCs & $\begin{array}{l}\text { Cardiogenesis/endothelial cell differentiation; } \\
\text { increased endodermal differentiation }\end{array}$ & {$[31] ;[32]$} \\
\hline Elastic modulus & $\begin{array}{l}\text { Soft/hard matrix; decreased } \\
\text { substrate stiffness; increased ECM } \\
\text { stiffness; decreased/increased } \\
\text { matrix rigidity; substrate stiffness } \\
\text { gradient; soft hydrogel substrates; } \\
\text { soft substrates }\end{array}$ & $\begin{array}{l}\text { hMSCs; rat NPCs; hPSCs; } \\
\text { murine mammary gland } \\
\text { cells; hMSCs; mMuSCs; } \\
\text { mESCs }\end{array}$ & $\begin{array}{l}\text { Neurogenesis/osteogenesis; increased neuronal } \\
\text { differentiation; increased cell and colony spreading; } \\
\text { TGF- } \beta 1 \text {-induced apoptosis/EMT; migration } \\
\text { up stiffness gradient; self-renewal and in vivo } \\
\text { regeneration; homogeneous self-renewal and } \\
\text { downregulated cell tractions }\end{array}$ & $\begin{array}{l}\text { [37]; [38; [39]; [40]; } \\
\quad \text { [41]; [43]; [44] }\end{array}$ \\
\hline $\begin{array}{l}\text { Dynamic mechanical } \\
\text { forces }\end{array}$ & $\begin{array}{l}\text { Local cell traction on non-linear } \\
\text { elastic fibrin gel; cell } \\
\text { compression; cell-cortex tension; } \\
\text { stretch-induced TIP-1/TIP-3 } \\
\text { expression; cyclic biaxial strain; } \\
\text { equiaxial/uniaxial strain; dynamic } \\
\text { hydrogel stiffening; shear stress; } \\
\text { shear stress; laminar shear stress; } \\
\text { fluid shear stress }\end{array}$ & $\begin{array}{l}\text { hMSCs; Drosophila germ } \\
\text { cells; zebrafish; lung EMCs; } \\
\text { hESCs; human bone } \\
\text { marrow MSCs; chicken } \\
\text { cardiomyocytes; hEPCs; } \\
\text { mEMCs; mESCs; mESCs }\end{array}$ & 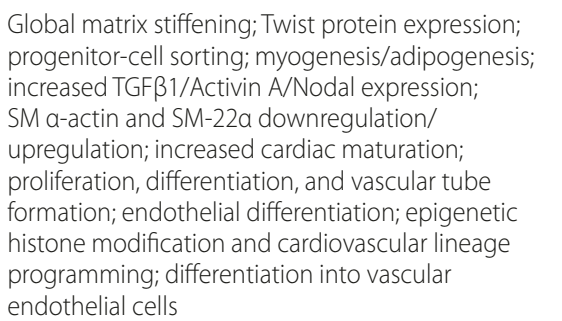 & $\begin{array}{c}\text { [42]; [50]; [51]; } \\
\text { [52]; [53]; [54]; } \\
\text { [58]; [61]; [62]; } \\
{[63] ;[64]}\end{array}$ \\
\hline
\end{tabular}

ECM, extracellular matrix; EGF, epidermal growth factor; EMC, embryonic mesenchymal cell; EMT, epithelial-mesenchymal transition; hEPC, human endothelial progenitor cell; $h E S C$, human embryonic stem cell; $H$ h, hedgehog; hMSC, human mesenchymal stem cell; $h P S C$, human pluripotent stem cell; LIF, leukemia inhibitory factor; MAPK, mitogen-activated protein kinase; mEMC, mouse embryonic mesenchymal cell; mESC, mouse embryonic stem cell; mMuSC, mouse muscle stem cell; MSC, mesenchymal stem cell; NPC, neural progenitor cell; NT-3, neurotrophic factor 3; PDGF, platelet-derived growth factor; RGD, arginine-glycine-asparagine peptide; SCF, stem cell factor; Shh, sonic hedgehog; SM, smooth muscle; STAT3, signal transducer and activator of transcription 3; TGF- $\beta$, transforming growth factor-beta; TIP, tension-induced/inhibited protein;VEGF, vascular endothelial growth factor; VEGFR2, vascular endothelial growth factor receptor 2.

NSCs in the subventricular zone of the lateral ventricles in the adult rodent brain differentiated into migratory cells that secreted MMPs at elevated levels [56]. Blocking the expression of these proteins inhibited differentiation of the NSCs, indicating that the cells require matrix remodeling to proceed with their differentiation and subsequent migration into injured areas of the brain. MSCs localized to bone marrow have also been shown to secrete MMPs to facilitate infiltration of sites of tissue damage, inflammation, or neoplasia before undergoing differentiation [57]. In addition to experiencing a decrease in ECM integrity, cells can experience ECM stiffening (for example, an approximately 10-fold increase in stiffness during cardiac maturation). Young and Engler [58] created a hyaluronic acid poly(ethylene glycol) hydrogel that could undergo stiffening over a two-week period and found that pre-cardiac cells within the gel underwent a significantly higher increase in maturation both expression of muscle markers and assembly into muscle fibers - than corresponding cells seeded on static hydrogels. The development of hydrogels in which crosslinks are photosensitive has enabled investigators to vary stiffness in time and space, powerful capabilities that will enable further advances in the field $[59,60]$.

Another form of dynamic stress is shear flow, most often associated with the circulatory system. The earliest study of shear on stem cell fate determined that flow promotes maturation and capillary assembly of endothelial progenitor cells [61]. Subsequent studies showed that shear flow can induce differentiation of other stem cell types, including endothelial cell specification from murine embryonic MSCs [62] and vascular endothelial cell lineage commitment from ESCs [63,64]. Each of these properties and parameters of the niche (summarized 
in Table 1) offers opportunities to control cell fate for downstream therapeutic application.

\section{Conclusions}

Understanding the properties and effects of each complex component of a local stem cell microenvironment is an essential step toward understanding the stem cell itself. In particular, the ability of a stem cell to respond to spatiotemporally varying biochemical cues and distinct mechanical and physical stimuli within its surroundings is being increasingly recognized and will continue to be elucidated in the years to come. The effect of substrate stiffness on stem cell fate has been increasingly appreciated in recent years, and other facets of the niche's solid phase - including spatial organization in the presentation of biochemical information, electrostatics [65], and biomolecular transport [66] - will increasingly be investigated. While technological limitations in the ability to control, quantify, and image these properties currently exist, advances in super-resolution microscopy may be combined with stem cell research to enable considerable progress [67].

Furthermore, an appreciation of these interactive processes in natural tissue may greatly aid the development of stem cell therapies to treat numerous human diseases. For example, this basic knowledge may enable therapeutic modulation of endogenous stem cells via alterations in the niche as well as offer opportunities to create more effective large-scale culture systems and bioreactors to expand and differentiate stem cells. Furthermore, the creation of in vitro cell and tissue equivalents of therapeutically relevant organs, enabled by the technological advances and optimized model culture systems, will enable both basic and therapeutic investigations of human disease biology. Therefore, as is evidenced by an increasing number of important studies, a blend of biology, chemistry, physics, and engineering can empower progress in both basic and translational directions.

This article is part of a thematic series on Physical influences on stem cells edited by Gordana Vunjak-Novakovic. Other articles in the series can be found online at http://stemcellres.com/series/physical

\section{Abbreviations}

3D, three-dimensional; EB, embryoid body; ECM, extracellular matrix; EMT, epithelial-mesenchymal transition; hESC, human embryonic stem cell; HSPC, hematopoietic stem and progenitor cell; LIF, leukemia inhibitory factor; mESC, mouse embryonic stem cell; MMP, matrix metalloproteinase; MSC, mesenchymal stem cell; NSC, neural stem cell; PDGF, platelet-derived growth factor; PDMS, polydimethylsiloxane; RGD, arginine-glycine-asparagine; Shh, sonic hedgehog; TGF, transforming growth factor; TIP-1, tension-induced/ inhibited protein-1; VEGF, vascular endothelial growth factor.

\section{Competing interests}

DVS is an inventor on a patent involving polyvalent ligands as potent activators of cellular signalling, and holds founder's stock in a company that is developing this commercially. AC declares no competing interests.
Authors' contributions

AC wrote the manuscript with helpful feedback and editing by DVS.

\section{Acknowledgments}

This review was supported by a training grant from the California Institute for Regenerative Medicine (T1-00007) and by NIH R01NS074831.

Published: 14 December 2012

\section{References}

1. Schofield R: The relationship between the spleen colony-forming cell and the haemopoietic stem cell. Blood Cells 1978, 4:7-25.

2. Xie T, Spradling AC: A niche maintaining germ line stem cells in the Drosophila ovary. Science 2000, 290:328-330.

3. Ye S, Luo Y, Lu W, Jones RB, Linhardt RJ, Capila I, Toida T, Kan M, Pelletier H, McKeehan WL: Structural basis for interaction of FGF-1, FGF-2, and FGF-7 with different heparan sulfate motifs. Biochemistry 2001, 40:14429-14439.

4. Khachigian LM, Chesterman CN: Platelet-derived growth factor and alternative splicing: a review. Pathology 1992, 24:280-290.

5. Hasan M, Najjam S, Gordon MY, Gibbs RV, Rider CC: IL-12 is a heparinbinding cytokine. J Immunol 1999, 162:1064-1070.

6. Chang SC, Mulloy B, Magee Al, Couchman JR: Two distinct sites in sonic Hedgehog combine for heparan sulfate interactions and cell signaling functions. J Biol Chem 2011, 286:44391-44402.

7. Tayalia P, Mooney DJ: Controlled growth factor delivery for tissue engineering. Adv Mater 2009, 21:3269-3285.

8. Saha K, Schaffer DV: Signal dynamics in Sonic hedgehog tissue patterning. Development 2006, 133:889-900.

9. Chen TT, Luque A, Lee S, Anderson SM, Segura T, Iruela-Arispe ML: Anchorage of VEGF to the extracellular matrix conveys differential signaling responses to endothelial cells. J Cell Bio/ 2010, 188:595-609.

10. Kuhl PR, Griffith-Cima LG: Tethered epidermal growth factor as a paradigm for growth factor-induced stimulation from the solid phase. Nat Med 1996, 2:1022-1027.

11. Ho JE, Chung EH, Wall S, Schaffer DV, Healy KE: Immobilized sonic hedgehog $\mathrm{N}$-terminal signaling domain enhances differentiation of bone marrowderived mesenchymal stem cells. J Biomed Mater Res A 2007, 83:1200-1208.

12. Willerth SM, Rader A, Sakiyama-Elbert SE: The effect of controlled growth factor delivery on embryonic stem cell differentiation inside fibrin scaffolds. Stem Cell Res 2008, 1:205-218.

13. Alberti K, Davey RE, Onishi K, George S, Salchert K, Seib FP, Bornhauser M, Pompe T, Nagy A, Werner C, Zandstra PW: Functional immobilization of signaling proteins enables control of stem cell fate. Nat Methods 2008, 5:645-650.

14. Mammen M, Choi S-K, Whitesides GM: Polyvalent interactions in biological systems: implications for design and use of multivalent ligands and inhibitors. Angew Chem Int Ed 1998, 37:2754-2794.

15. Kiessling LL, Gestwicki JE, Strong LE: Synthetic multivalent ligands in the exploration of cell-surface interactions. Curr Opin Chem Biol 2000, 4:696-703.

16. Gestwicki JE, Strong LE, Kiessling LL: Tuning chemotactic responses with synthetic multivalent ligands. Chem Biol 2000, 7:583-591.

17. Jones DS, Coutts SM, Gamino CA, Iverson GM, Linnik MD, Randow ME, TonNu HT, Victoria EJ: Multivalent thioether-peptide conjugates: B cell tolerance of an anti-peptide immune response. Bioconjug Chem 1999, 10:480-488.

18. Maheshwari G, Brown G, Lauffenburger DA, Wells A, Griffith LG: Cell adhesion and motility depend on nanoscale RGD clustering. J Cell Sci 2000, 113 (Pt 10):1677-1686.

19. Huebsch N, Arany PR, Mao AS, Shvartsman D, Ali OA, Bencherif SA, RiveraFeliciano J, Mooney DJ: Harnessing traction-mediated manipulation of the cell/matrix interface to control stem-cell fate. Nat Mater 2010, 9:518-526.

20. Vyas N, Goswami D, Manonmani A, Sharma P, Ranganath HA, VijayRaghavan K, Shashidhara LS, Sowdhamini R, Mayor S: Nanoscale organization of hedgehog is essential for long-range signaling. Cell 2008, 133:1214-1227.

21. Dore JJ Jr., Edens M, Garamszegi N, Leof EB: Heteromeric and homomeric transforming growth factor-beta receptors show distinct signaling and endocytic responses in epithelial cells. J Biol Chem 1998, 273:31770-31777.

22. Artavanis-Tsakonas S, Rand MD, Lake RJ: Notch signaling: cell fate control and signal integration in development. Science 1999, 284:770-776.

23. Pasquale EB: Eph receptor signalling casts a wide net on cell behaviour. Nat 
Rev Mol Cell Biol 2005, 6:462-475

24. Wall ST, Saha K, Ashton RS, Kam KR, Schaffer DV, Healy KE: Multivalency of Sonic hedgehog conjugated to linear polymer chains modulates protein potency. Bioconjug Chem 2008, 19:806-812.

25. Oh S, Brammer KS, Li YS, Teng D, Engler AJ, Chien S, Jin S: Stem cell fate dictated solely by altered nanotube dimension. Proc Natl Acad Sci U SA 2009, 106:2130-2135.

26. Dalby MJ, Gadegaard N, Tare R, Andar A, Riehle MO, Herzyk P, Wilkinson CD, Oreffo RO: The control of human mesenchymal cell differentiation using nanoscale symmetry and disorder. Nat Mater 2007, 6:997-1003.

27. Kulangara K, Yang Y, Yang J, Leong KW: Nanotopography as modulator of human mesenchymal stem cell function. Biomaterials 2012, 33:4998-5003.

28. Ungrin MD, Joshi C, Nica A, Bauwens C, Zandstra PW: Reproducible, ultra high-throughput formation of multicellular organization from single cell suspension-derived human embryonic stem cell aggregates. PLoS One 2008, 3:e1565.

29. Mohr JC, de Pablo JJ, Palecek SP: 3-D microwell culture of human embryonic stem cells. Biomaterials 2006, 27:6032-6042

30. Karp JM, Yeh J, Eng G, Fukuda J, Blumling J, Suh KY, Cheng J, Mahdavi A Borenstein J, Langer R, Khademhosseini A: Controlling size, shape and homogeneity of embryoid bodies using poly(ethylene glycol) microwells. Lab Chip 2007, 7:786-794.

31. Hwang YS, Chung BG, Ortmann D, Hattori N, Moeller HC, Khademhosseini A Microwell-mediated control of embryoid body size regulates embryonic stem cell fate via differential expression of WNT5a and WNT11. Proc Natl Acad Sci U S A 2009, 106:16978-16983.

32. Bauwens CL, Peerani R, Niebruegge S, Woodhouse KA, Kumacheva E, Husain $\mathrm{M}$, Zandstra PW: Control of human embryonic stem cell colony and aggregate size heterogeneity influences differentiation trajectories. Stem Cells 2008, 26:2300-2310.

33. Katzberg AA: Distance as a factor in the development of attraction fields between growing tissue in culture. Science 1951, 114:431-432.

34. Weiss P, Garber B: Shape and movement of mesenchyme cells as function of the physical structure of the medium: contributions to a quantitative morphology. Proc Natl Acad Sci U S A 1952, 38:264-280.

35. Warshaw DM, Mulvany MJ, Halpern W: Mechanical and morphological properties of arterial resistance vessels in young and old spontaneously hypertensive rats. Circ Res 1979, 45:250-259.

36. Elkin BS, Azeloglu EU, Costa KD, Morrison B 3rd: Mechanical heterogeneity of the rat hippocampus measured by atomic force microscope indentation. J Neurotrauma 2007, 24:812-822.

37. Engler AJ, Sen S, Sweeney HL, Discher DE: Matrix elasticity directs stem cell lineage specification. Cell 2006, 126:677-689.

38. Saha K, Keung AJ, Irwin EF, Li Y, Little L, Schaffer DV, Healy KE: Substrate modulus directs neural stem cell behavior. Biophys J 2008, 95:4426-4438.

39. Keung AJ, Asuri P, Kumar S, Schaffer DV: Soft microenvironments promote the early neurogenic differentiation but not self-renewal of human pluripotent stem cells. Integr Biol (Camb) 2012, 4:1049-1058.

40. Leight JL, Wozniak MA, Chen S, Lynch ML, Chen CS: Matrix rigidity regulates a switch between TGF-beta1-induced apoptosis and epithelialmesenchymal transition. Mol Biol Cell 2012, 23:781-791.

41. Tse JR, Engler AJ: Stiffness gradients mimicking in vivo tissue variation regulate mesenchymal stem cell fate. PLoS One 2011, 6:e15978.

42. Winer JP, Oake S, Janmey PA: Non-linear elasticity of extracellular matrices enables contractile cells to communicate local position and orientation. PLoS One 2009, 4:e6382.

43. Gilbert PM, Havenstrite KL, Magnusson KE, Sacco A, Leonardi NA, Kraft P, Nguyen NK, Thrun S, Lutolf MP, Blau HM: Substrate elasticity regulates skeletal muscle stem cell self-renewal in culture. Science 2010, 329:1078-1081.

44. Chowdhury F, Li Y, Poh YC, Yokohama-Tamaki T, Wang N, Tanaka TS: Soft substrates promote homogeneous self-renewal of embryonic stem cells via downregulating cell-matrix tractions. PLoS One 2010, 5:e15655.

45. Fu J, Wang YK, Yang MT, Desai RA, Yu X, Liu Z, Chen CS: Mechanical regulation of cell function with geometrically modulated elastomeric substrates. Nat Methods 2010, 7:733-736

46. Keung AJ, de Juan-Pardo EM, Schaffer DV, Kumar S: Rho GTPases mediate the mechanosensitive lineage commitment of neural stem cells. Stem Cells 2011, 29:1886-1897.

47. Kim TJ, Seong J, Ouyang M, Sun J, Lu S, Hong JP, Wang N, Wang Y: Substrate rigidity regulates $\mathrm{Ca} 2+$ oscillation via RhoA pathway in stem cells. $J$ Cell
Physiol 2009, 218:285-293

48. Dupont S, Morsut L, Aragona M, Enzo E, Giulitti S, Cordenonsi M, Zanconato F, Le Digabel J, Forcato M, Bicciato S, Elvassore N, Piccolo S: Role of YAP/TAZ in mechanotransduction. Nature 2011, 474:179-183.

49. Trappmann B, Gautrot JE, Connelly JT, Strange DG, Li Y, Oyen ML, Cohen Stuart MA, Boehm H, Li B, Vogel V, Spatz JP, Watt FM, Huck WT: Extracellularmatrix tethering regulates stem-cell fate. Nat Mater 2012, 11:642-649.

50. Farge E: Mechanical induction of Twist in the Drosophila foregut/ stomodeal primordium. Curr Biol 2003, 13:1365-1377.

51. Krieg M, Arboleda-Estudillo Y, Puech PH, Kafer J, Graner F, Muller DJ, Heisenberg CP: Tensile forces govern germ-layer organization in zebrafish. Nat Cell Biol 2008, 10:429-436.

52. Jakkaraju S, Zhe X, Pan D, Choudhury R, Schuger L: TIPs are tensionresponsive proteins involved in myogenic versus adipogenic differentiation. Dev Cell 2005, 9:39-49.

53. Saha S, Ji L, de Pablo JJ, Palecek SP: TGFbeta/Activin/Nodal pathway in inhibition of human embryonic stem cell differentiation by mechanical strain. Biophys J 2008, 94:4123-4133.

54. Park JS, Chu JS, Cheng C, Chen F, Chen D, Li S: Differential effects of equiaxial and uniaxial strain on mesenchymal stem cells. Biotechnol Bioeng 2004, 88:359-368

55. Gross J, Lapiere CM: Collagenolytic activity in amphibian tissues: a tissue culture assay. Proc Natl Acad Sci U S A 1962, 48:1014-1022.

56. Barkho BZ, Munoz AE, Li X, Li L, Cunningham LA, Zhao X: Endogenous matrix metalloproteinase (MMP)-3 and MMP-9 promote the differentiation and migration of adult neural progenitor cells in response to chemokines. Stem Cells 2008, 26:3139-3149.

57. Lu C, Li XY, Hu Y, Rowe RG, Weiss SJ: MT1-MMP controls human mesenchymal stem cell trafficking and differentiation. Blood 2010 , 115:221-229.

58. Young JL, Engler AJ: Hydrogels with time-dependent material properties enhance cardiomyocyte differentiation in vitro. Biomaterials 2011, 32:1002-1009.

59. Guvendiren M, Burdick JA: Stiffening hydrogels to probe short- and longterm cellular responses to dynamic mechanics. Nat Commun 2012, 3:792.

60. Kloxin AM, Benton JA, Anseth KS: In situ elasticity modulation with dynamic substrates to direct cell phenotype. Biomaterials 2010, 31:1-8.

61. Yamamoto K, Takahashi T, Asahara T, Ohura N, Sokabe T, Kamiya A, Ando J: Proliferation, differentiation, and tube formation by endothelial progenitor cells in response to shear stress. J Appl Physio/ 2003, 95:2081-2088

62. Wang $H$, Riha GM, Yan S, Li M, Chai H, Yang H, Yao Q, Chen C: Shear stress induces endothelial differentiation from a murine embryonic mesenchymal progenitor cell line. Arterioscler Thromb Vasc Biol 2005, 25:1817-1823.

63. Illi B, Scopece A, Nanni S, Farsetti A, Morgante L, Biglioli P, Capogrossi MC, Gaetano C: Epigenetic histone modification and cardiovascular lineage programming in mouse embryonic stem cells exposed to laminar shear stress. Circ Res 2005, 96:501-508.

64. Yamamoto K, Sokabe T, Watabe T, Miyazono K, Yamashita JK, Obi S, Ohura N, Matsushita A, Kamiya A, Ando J: Fluid shear stress induces differentiation of Flk-1-positive embryonic stem cells into vascular endothelial cells in vitro. Am J Physiol Heart Circ Physiol 2005, 288:H1915-1924.

65. Radisic M, Park H, Shing H, Consi T, Schoen FJ, Langer R, Freed LE, VunjakNovakovic G: Functional assembly of engineered myocardium by electrical stimulation of cardiac myocytes cultured on scaffolds. Proc Natl Acad Sci USA 2004, 101:18129-18134.

66. Carpenedo RL, Bratt-Leal AM, Marklein RA, Seaman SA, Bowen NJ, McDonald JF, McDevitt TC: Homogeneous and organized differentiation within embryoid bodies induced by microsphere-mediated delivery of small molecules. Biomaterials 2009, 30:2507-2515.

67. Shroff H, Galbraith CG, Galbraith JA, Betzig E: Live-cell photoactivated localization microscopy of nanoscale adhesion dynamics. Nat Methods 2008, 5:417-423.

doi:10.1186/scrt14

Cite this article as: Conway A, Schaffer DV: Biophysical regulation of stem

cell behavior within the niche. Stem Cell Research \& Therapy 2012, 3:50. 